\title{
HUBUNGAN ANTARA IKLIM ORGANISASI DENGAN SUBJECTIVE WELL-BEING PADA KARYAWAN DI PERUSAHAAN X
}

\author{
Erlinda Wongso Hartanto dan Jimmy Ellya Kurniawan \\ Program Studi Psikologi Universitas Ciputra
}

\begin{abstract}
Subjective well being (SWB) is one of important thing in human's life because it may correlate with higher productivity and a good social relationship. SWB is individual's evaluation of their experience for the whole picture or each domain of life including their satisfaction and feeling. For adult, work domain take most of the time each day. That is why situation at work might affect their evaluation. Evaluation at working situation called organizational climate. The aim of this paper is to investigate the correlation between organizational climate and subjective well being among employees. This study utilized quantitative approach with correlational design. Total number of the subject was 63 employees from $X$ company who were selected using population cluster sampling technique. Data collection tool was adapted from LSOCQ, SWLS and SPANE. Result showed that there was a positive correlation between organizational climate and subjective well-being among $X$ company's employees ( $r=$ $0.623, p=0.000 ; r=0.434, p=0.000$ ). Finding showed that employee who work in a good organization climate have a good subjective well-being. Finding also show that gender, age, income, status and education were believed to have a correlation with SWB on employee.
\end{abstract}

Keywords : Organizational Climate, Subjective well being, Employee

\begin{abstract}
Abstrak: Subjective well being (SWB) adalah hal penting yang ingin dicapai dalam kehidupan karena dapat meningkatkan produktivitas dan hubungan sosial yang baik. SWB merupakan evaluasi kepuasan dan afeksi individu terhadap pengalaman hidup mereka baik secara keseluruhan maupun per domain kehidupan. Domain yang memakan waktu paling banyak dalam kehidupan manusia dewasa adalah domain kerja. Evaluasi individu terhadap domain pekerjaannya disebut iklim organisasi. Oleh karena itu diduga bahwa iklim organisasi dapat mempengaruhi tingkat SWB karyawan. Tujuan dari penelitian ini adalah mengetahui hubungan antara iklim organisasi dengan SWB karyawan. Penelitian menggunakan pendekatan kuantitatif dengan desain korelasian. Subjek terdiri dari 63 karyawan perusahaan X dan dipilih menggunakan cluster sampling. Alat ukur iklim organisasi menggunakan LSOCQ sementara SWB menggunakan SWLS dan SPANE. Hasil menunjukan ada korelasi positif antara iklim organisasi dengan SWB $(r=0.623, p=0.000 ; r=0.434, p=0.000)$. semakin baik iklim di suatu organisasi maka semakin tinggi SWB karyawan dan begitu sebaliknya.
\end{abstract}

Kata Kunci : Iklim organisasi, Subjective well being, karyawan

Kebahagiaan adalah hal yang penting dalam kehidupan umat manusia. Menurut Aristotles kebahagiaan adalah tujuan dari kehidupan (dalam Ningsih, 2013). Hanya saja tujuan dari kebahagiaan setiap individu berbeda-beda tergantung pada persepsi dan makna kebahagiaan bagi setiap individu.

Korespondensi tentang artikel ini dapat dialamatkan jimmy.ellya@ciputra.ac.id
Menurut Luthans (dalam Mujamiasih, 2013) istilah kebahagiaan ini banyak di bahas didalam psikologi positif. Dalam ilmu psikologi istilah kebahagiaan lebih sering di sebut sebagai subjective well being (SWB) karena lebih bersifat operasional. Hal ini didukung oleh Seligman dan

kepada Jimmy Ellya Kurniawan melalui e-mail. 
Csikszentmihalyi (dalam Mujamiasih, 2013) yang mengatakan bahwa SWB lebih ilmiah dalam mengartikan kebahagiaan dan SWB dianggap lebih luas serta konkrit dalam membahas kebahagiaan. Oleh karena itulah, dalam penelitian ini peneliti menggunakan istilah SWB.

Setiap manusia memimpikan SWB dan setiap individu berhak untuk memilikinya. Namun, untuk mencapainya ternyata tidaklah mudah. Sepanjang hidupnya manusia akan selalu dihadapkan pada permasalahan-permasalahan kehidupan. Salah satu contohnya adalah permasalahan di tempat kerja. Seperti yang diungkap oleh Rimanews.com (Yus, 2011) dan Surya Online (Suyanto, 2012) mengenai pertikaian internal yang terjadi pada PT Freeport Indonesia. Tidak hanya itu, dari pernyataan sumber yang telah diwawancarai ternyata dunia pekerjaan masih kerap kali mendatangkan permasalahan tersendiri. Fenomena-fenomena di atas juga turut terjadi di perusahan $\mathrm{X}$. Hal ini diketahui melalui hasil wawancara peneliti dengan seorang karyawan perusahaan $\mathrm{X}$ dimana beliau mengatakan bahwa permasalahan yang komplek di tempat kerja turut mempengaruhi dirinya ketika pulang ke rumah.

Dari fenomena-fenomena yang diangkat diatas dapat diketahui bahwa karyawan merasa tidak puas terhadap perlakuan perusahaan, atasan maupun rekanrekannya. Nitisemito (dalam Mubiono, 2010) menyatakan bahwa ketidakpuasan karyawan bisa bersifat material seperti upah atau gaji maupun non material seperti penghargaan, perasaan dipedulikan dan kesempatan berkontribusi dalam perusahaan. Kepuasan material maupun non material tersebut merupakan kebutuhan dan harapan/tujuan karyawan. Terpenuhi atau tidak terpenuhinya kebutuhan dan harapan dapat mempengaruhi kebahagiaan subjektif atau Subjective Well Being. Didukung oleh Mc Gregor dan Little (dalam Nayana, 2013) yang mengatakan bahwa salah satu pendekatan teori untuk mengukur Subjective Well Being adalah terpenuhinya kebutuhan dan harapan pekerja dari domain pekerjaannya.
Definisi SWB menurut Diener (1984) adalah konstruk yang didasarkan dari pengalaman subjektif individu. SWB adalah evaluasi sisi afektif dan evaluasi sisi kognitif dari kehidupan seorang individu. Sisi afektif meliputi emosi, suasana hati dan perasaan individu sedangkan sisi kognitif meliputi refleksi pengalaman hidup individu.

Dengan demikian maka SWB memiliki makna yang lebih luas bila dibandingkan dengan kepuasan kerja semata. Hal ini dikarenakan bahwa kepuasan kerja menurut Timmreck (dalam Muhadi, 2007) merupakan terpenuhi atau tidaknya harapan karyawan pada pekerjaannya. Sementara SWB merupakan tahapan lanjutan dari kepuasan kerja dimana pengalaman positif dari kepuasan bekerja itu bisa membantu individu untuk melihat hidupnya secara positif dan merasakan kebahagiaan subjektif.

Kebahagiaan subjektif ini tentunya penting bagi seorang individu bahkan Pavot dan Diener (dalam Dewi \& Utami, n.d) mengatakan bahwa SWB menjadi salah satu prediktor kualitas hidup seorang individu karena SWB dapat mempengaruhi kesuksesan pribadi dalam berbagai bidang kehidupan. Seseorang yang dikatakan memiliki SWB yang tinggi menurut Diener dan Lucas (dalam Ryan \& Deci, 2001) adalah ketika seorang individu menilai kepuasan hidupnya tinggi, merasakan afek positif lebih sering bila dibandingkan dengan afek negatif (dalam Gatari, 2008). Sementara itu Watson, Clark, dan Tellegen (dalam Gatari, 2008) mengatakan bahwa seseorang dengan SWB yang tinggi cenderung memiliki energi yang baik, dapat berkonsentrasi secara fokus dan memandang keterlibatan sebagai suatu hal yang menyenangkan. Dalam menghadapi tekanan pun, menurut Diener, Biswas dan Tamir (dalam Dewi \& Utami, n.d.) seseorang dengan SWB yang baik dapat berhasil melakukan adaptasi dan coping yang mampu membuatnya merasa lebih baik.

Bila pemahaman mengenai konsep SWB ini digunakan untuk menilai kebahagiaan dan kesejahteraan dari contoh kasus para karyawan di atas dapat dikatakan 
bahwa karyawan belum sejahtera. Persepsi karyawan mengenai hubungan sosial dan situasi dalam suatu organisasi dinamakan iklim organisasi. Iklim organisasi menurut Smither (dalam Yuliana, 2007) merupakan keadaan dimana karyawan merasakan berbagai situasi dalam lingkungan organisasi sehingga menimbulkan interpretasi tertentu terhadap organisasi. Hingga saat ini masih belum dijumpai penelitian yang menghubungkan antara iklim organisasi dengan subjective well being secara langsung. Namun, dari beberapa literatur dapat ditemukan asumsi bahwa ada hubungan antara iklim organisasi dengan subjective well being. Penelitian mengenai iklim organisasi sangat banyak dan beberapa penelitiannya dikaitkan dengan kepuasan kerja. Salah satunya adalah penelitian oleh Wibisono (2008) yang mengatakan bahwa iklim organisasi memang memiliki pengaruh terhadap kepuasan kerja karyawan. Sementara itu, kepuasan kerja itu sendiri merupakan salah satu faktor yang mempengaruhi subjective well being seseorang. Hal ini dibuktikan melalui penelitian yang dilakukan oleh Judge dan Locke (dikutip oleh Russel dalam Ariati, 2010) yang menemukan adanya hubungan antara kepuasan kerja dengan subjective well being pada perawat. Setelah itu Judge dan Locke (dalam Ariati, 2010) juga mengatakan bahwa apabila seorang individu merasa sejahtera maka mereka dapat dengan mudah mengumpulkan dan mengingat informasi mengenai pekerjaan yang dapat mempengaruhi kinerja individu. Berdasarkan dari penjabaran-penjabaran tersebut dapat diasumsikan bahwa ada hubungan positif antara iklim organisasi dengan subjective well being. Oleh karena itu, semakin baik iklim organisasi suatu perusahaan maka subjective well being karyawan perusahaan tersebut semakin baik pula.

\section{Subjective well-being (SWB)}

Menurut Diener (dalam Baumgardner \& Crothers, 2010) definisi dari SWB adalah evaluasi personal terhadap pengalaman hidupnya yang didasarkan pada domain- domain tertentu ataupun keseluruhan hidupnya secara global baik secara kognitif maupun secara afeksi.

\section{Dimensi SWB}

Menurut Diener, Suh, Lucas, \& Smith (1999) dimensi dalam SWB terbagi menjadi dua yaitu, evaluasi kognitif dan evaluasi afeksi. Evaluasi kognitif dalam SWB diartikan sebagai evaluasi terhadap kepuasan hidup (life satisfaction) dimana evaluasi kognitif ini terbagi lagi menjadi dua yaitu evaluasi kepuasan secara global dan evaluasi kepuasan terhadap domain tertentu dalam kehidupan. Sementara evaluasi afeksi individu ini menyangkut perasaan yang ditimbulkan dari hasil merefleksikan pengalaman atau peristiwa dalam hidup seseorang. Evaluasi afeksi ini terbagi menjadi dua yaitu afek positif dan afek negatif (Diener, 1984). Faktor-faktor yang berpengaruh terhadap SWB menurut Diener (1984) adalah Faktor -faktor yang mempengaruhi SWB.

Faktor-faktor yang berpengaruh terhadap SWB menurut Diener (1984) adalah:

\section{Faktor Demografis}

Menurut Diener efek dari faktor demografis ini sifatnya kecil terhadap SWB seseorang. Hanya saja, faktor demografis ini digunakan untuk membedakan antara individu yang memiliki tingkat SWB sedang (merasa biasa-biasa saja) dengan individu yang memiliki tingkat SWB tinggi (merasa sangat bahagia). Faktor demografis ini terdiri enam aspek yaitu :

a. Pendapatan. Pernyataan ini juga turut ditunjang oleh penelitian dan bukti-bukti pendahulu yang mengatakan bahwa kepuasan terhadap pendapatan dapat mempengaruhi kebahagiaan personal individu (dikutip dari Braun, 1977 dalam Diener, 1984).

b. Pernikahan dan keluarga. Berdasarkan dari penelitian para ahli didapatkan pernyataan bahwa manusia yang telah menikah memiliki SWB yang lebih besar daripada mereka yang tidak menikah 
c. Umur. Bradburn mengatakan bahwa ada kecenderungan mereka yang berusia muda lebih bahagia daripada mereka yang telah berumur (dalam Diener, 1984). Namun pernyataan ini ternyata telah disanggah oleh beberapa peneliti yang mengatakan bahwa umur tidaklah mempengaruhi kebahagiaan personal (dikutip dari Alston et al dalam Diener, 1984). Hingga Braun (1977, dalam Diener, 1984) mengatakan melalui penelitiannya bahwa ternyata seseorang dengan usia yang lebih muda dilaporkan memiliki level afek positf dan negatif yang lebih kuat daripada orang yang telah berumur. Namun, seseorang yang telah berumur dilaporkan lebih memiliki level kebahagiaan lebih kuat terhadap kebahagiaan secara keseluruhan bukan hanya terhadap afek positif dan negatif.

d. Gender. Gender kerap kali dikatakan mempengaruhi kebahagiaan. Dilaporkan bahwa wanita memiliki kecenderungan lebih mudah terpengaruhi oleh afek negatif daripada pria. Namun ternyata wanita juga dilaporkan lebih menikmati kebahagiaan daripada pria ( Braun et al dalam Diener, 1984).

e. Ras. Pembahasan mengenai ras ini terbatas hanya pada ras kulit hitam dan ras kulit putih di Amerika Serikat dimana dikatakan bahwa ras kulit hitam memiliki SWB yang lebih rendah daripada ras kulit putih.

f. Employment. Campbell et al (dalam Diener, 1984) dalam penelitiannya mengatakan bahwa kelompok orang yang tidak bekerja adalah kelompok yang paling tidak bahagia secara personal namun hal ini tidaklah berarti bahwa mereka yang bekerja di rumah tidak bahagia.

g. Pendidikan. Dalam penelitian oleh Campbell (1981 dalam Diener, 1984) diketahui bahwa pendidikan memiliki pengaruh terhadap SWB hanya saja efek dari pendidikan terhadap SWB dikatakan tidak terlalu kuat.

h. Religiusitas. Menurut Cameron (dalam Diener, 1984) religiusitas berhubungan erat dengan perasaan atau emosi positif yang dapat mempengaruhi tingkat SWB.

\section{Faktor Genetik}

Walaupun definisi SWB adalah evaluasi penilaian akan peristiwa-peristiwa yang mempengaruhi dalam hidup seseorang, Diener et al (1999) mengatakan bahwa sebenarnya seorang individu memiliki kemampuan untuk beradaptasi terhadap pengaruh-pengaruh tersebut dan kembali lagi ke dalam keadaan "set-point" yang ditentukan secara biologis. Oleh karena itulah timbul adanya konsistensi dalam diri individu yang merupakan peran dari faktor biologis.

Selain itu, Lykken dan Tellegen ( dalam Diener et al, 1999) menemukan bahwa 40\%-55\% variasi dalam SWB saat ini bisa dijelaskan dengan teori genetika dan $80 \%$ dari long-term SWB bersifat warisan atau dapat diwariskan.

\section{Kepribadian}

Diener mengatakan bahwa kepribadian merupakan faktor terkuat dan yang paling konsisten sebagai prediktor untuk SWB. Kepribadian yang paling banyak dibahas dan dikaitkan dengan SWB adalah kepribadian extraversion dan neuroticism dimana dikatakan bahwa seseorang dengan tipe kepribadian extraversion memiliki korelasi positif dengan afek positif sementara neuroticism berkorelasi dengan afek negatif (Diener, 1984).

\section{Dukungan sosial}

Menurut Arygle (dalam Gatari, 2008) dukungan sosial adalah salah satu variabel penentu SWB. Hal ini dibuktikan melalui penelitian oleh Walen dan Lachman (dalam Gatari, 2008) yang menemukan bahwa persepsi individu terhadap kualitas dukungan sosial yang dimilikinya menjadi penjelasan terhadap sebagian besar faktor-faktor yang mempengaruhi kepuasan hidup dan afek positif yang dirasakan. Didukung oleh Goodwin dan Plasa (2000) ternyata turut menemukan adanya korelasi antara persepsi dukungan sosial dengan kepuasan hidup. 
Sedangkan penemuan yang mengatakan bahwa seseorang merasakan afek positif ketika mendapat dukungan sosial yang baik dari teman dan atasan dalam dunia kerja didapatkan dari hasil penelitian Iverson, Olekalns dan Erwin (dalam Boehm \& Lyubomirsky, 2008).

\section{Pengaruh budaya}

Diener, Suh, Lucas, \& Smith (1999) menjelaskan bahwa hubungan antara pengaruh budaya dengan SWB adalah terletak pada perbedaan persepsi masyarakat. Ditambahkan pula bahwa masyarakat individualis mementingkan kebahagiaannya sendiri sementara masyarakat kolektivis lebih menekankan pada nilai harmoni dan penghormatan.

\section{Proses kognitif}

Proses kognitif ini mempengaruhi SWB dalam hal bagaimana seorang individu memandang dunia, bagaiamana proses berpikir individu dalam memaknai suatu fenomena (menyenangkan atau tidak) serta seberapa akurat dan efisien seseorang dalam memproses informasi

\section{Iklim Organisasi}

Litwin dan Stringer (dalam Holloway, 2012) mendefinisikan iklim organisasi sebagai suatu kesimpulan persepsi individu yang bekerja dalam suatu organisasi.

\section{Dimensi Iklim Organisasi}

Menurut Litwin dan Stringer (dalam Hardjana, 2006) dimensi iklim organisasi adalah :

1. Struktur. Struktur termasuk dalam dimensi iklim organisasi karena struktur organisasi sangat mempengaruhi persepsi karyawan. (Holloway, 2012). Struktur adalah kejelasan mengenai peraturan, regulasi, prosedur, porsi pekerjaan setiap individu serta posisi jabatan masingmasing karyawan (Litwin \& Stringer, 1968 dalam Yoo, Huang, \& Lee, 2012)

2. Tanggung jawab. Tanggung jawab adalah persepsi karyawan mengenai tuntutan dalam pekerjaannya (Hardjana, 2006). Iklim organisasi dapat mempengaruhi ada tidaknya tanggung jawab dalam diri karyawan. Dengan iklim organisasi yang positif, karyawan dapat menjadi pimpinan atas dirinya sendiri, dapat menjalankan tugas dan membuat keputusan secara mandiri (Yuliana, 2007).

3. Kehangatan. Persepsi yang baik terhadap suasana dalam organisasi. Individu merasa diterima dan disukai. Suasana dalam organisasi bersifat informal dan penuh rasa pertemanan (Litwin \& Stringer, 1968 dalam Yoo et al, 2012)

4. Dukungan. Dukungan adalah sikap yang diberikan oleh atasan maupun sesama rekan kerja yang dapat meredakan kecemasan dan kebingungan akan pekerjaan. Karyawan (terutama karyawan baru) yang mendapatkan kehangatan dan dukungan dalam organisasi memperlihatkan loyalitas yang lebih tinggi terhadap organisasi (Hardjana, 2006). Menurut penelitian McGregor (Hardjana, 2006) adanya dukungan dalam iklim organisasi merupakan faktor penting dalam praktek pelaksanaan pekerjaan.

5. Reward. Pemberian reward tentunya sangat mempengaruhi persepsi karyawan terhadap organisasinya. Reward bisa menjadi bentuk apresiasi dan dukungan dari atasan terhadap hasil pekerjaan karyawan (Holloway, 2012).

6. Berani berkonflik. Berani berkonflik adalah situasi dimana atasan ataupun rekan kerjanya mau mendengarkan pendapat yang berbeda dan mau berkonflik untuk mendapatkan pemecahan masalah daripada hanya membiarkannya saja (Litwin \& Stringer dalam Yoo et al, 2012)

7. Standar kinerja. Standar kinerja karyawan ini sangat dipengaruhi oleh tujuan dan motivasi dalam diri individu. Standar kinerja ini berkaitan dengan pengukuran persepsi individu mengenai pentingnya kinerja dan harapan individu terhadap pekerjaannya. (Hardjana, 2006). 
8. Identitas organisasi. Identitas organisasi adalah persepsi perasaan karyawan bahwa dirinya merupakan bagian dari organisasi. Identitas organisasi ini menunjukan tingkat loyalitas karyawan terhadap organisasinya. Seberapa bangga karyawan terhadap organisasi tersebut. (Hardjana, 2006).

9. Risiko. Dimensi risiko merupakan persepsi karyawan mengenai adanya tantangan berisiko yang dapat diambil dalam pekerjaannya (Yoo et al,2012). Pengambilan risiko yang terencana ini dapat menstimulus karyawan untuk berprestasi. Menurut Litwin (dalam Hardjana, 2006) pengambilan risiko ini dipengaruhi oleh motivasi intrinsik karyawan untuk berprestasi.

\section{Hubungan antara iklim organisasi dan SWB}

Menilai dari definisi antara SWB dan iklim organisasi didapat kesamaan bahwa keduanya sama-sama membahas mengenai persepsi. Selain itu, menurut Rode (dalam page, 2005) dan hasil penelitian dari Litwin dan Stringer (Hardjana,2006) iklim organisasi sangat mempengaruhi kepuasan kerja yang mana kepuasan dalam bekerja tersebut menjadi salah satu penentu kepuasan hidup secara keseluruhan yang berdampak pada tingkat SWB individu. Dimensi-dimensi dalam iklim organisasi bila dapat berjalan dengan baik dapat meningkatkan kebahagiaan subjektif karyawan. Hal ini dikarenakan dimensi menurut Litwin dan Stringer memang berfokus pada bagaimana faktor dalam organisasi mempengaruhi seseorang secara personal. Diener (2000) mengatakan bahwa SWB ditentukan oleh cara individu dalam mengevaluasi informasi atau kejadian yang terjadi. Oleh karena itu disimpulkan bahwa dimensi-dimensi iklim organisasi menjadi input dalam proses pengevaluasian SWB karyawan.

\section{METODE}

\begin{tabular}{ccr} 
Penelitian ini & \multicolumn{2}{r}{ menggunakan } \\
pendekatan kuantitatif & dengan desain
\end{tabular}

korelasional dan menggunakan metode kuesioner.

\section{Populasi dan Sampel}

Populasi dalam penelitian ini adalah karyawan di perusahaan $X$. Sementara kriteria pemilihan sampel dalam penelitian kali ini adalah karyawan tetap perusahaan $X$ yang telah bekerja minimal satu tahun di perusahaan X. Dalam penelitian ini, peneliti akan menggunakan metode pengambilan sampel dengan cara random berkelompok.

Penelitian dilakukan di perusahaan $\mathrm{X}$ yang merupakan salah satu perusahaan real estate yang berfokus pada penyewaan stand dan tenant di sebuah mall di Surabaya. Perusahaan X memiliki karyawan sebanyak 118 orang yang terbagi-bagi menjadi beberapa divisi. Divisi-divisi tersebut meliputi divisi HRD, tenant design, promosi, finance, operational, teknisi dan services.

\section{Teknik Pengumpulan Data}

Teknik pengambilan data dilakukan dengan melakukan penyebaran kuesioner kepada responden. Instrumen pneleitian menggunakan skala iklim organisasi yang diadaptasi dari Litwin and Stringer Organization Climate Quesionare (LSOCQ). Semakin tinggi skor yang didapat dari adaptasi alat ukur LSOCQ maka semakin baik pula iklim organisasi dalam suatu perusahaan. Sementara Untuk mengukur komponen-komponen dari SWB akan digunakan skala ukur yang dimodifikasi dari alat ukur milik Diener yaitu, SWLS (Satisfaction with Life Scale) dan SPANE (Scale of Positive and Negative Experience).

\section{Teknik Analisis Data}

Dalam penelitian ini, uji statistik yang digunakan merupakan uji korelasi Pearson Product Moment dengan menggunakan bantuan program SPSS.Sementara uji normalitas menggunakan uji KolmogorovSmirnov. 


\section{HASIL DAN PEMBAHASAN}

Uji korelasi antara iklim organisasi dengan SWB karyawan di perusahaan $X$ dilakukan setelah peneliti memperoleh keseluruhan data dari sampel. Hasil pengujian yang menggunakan pearson product moment menunjukkan bahwa $\mathrm{H} 1$ diterima $(r=0.623$ dan $0.434 ; p=0.000$ dan $0.000 ; r>0.3, p<0.05)$. Hal ini berati bahwa ada hubungan antara iklim organisasi dengan
SWB karyawan di perusahaan X. Semakin baik iklim organisasi perusahaan maka semakin tinggi tingkat SWB karyawan pada perusahaan tersebut. Demikian pula sebaliknya, semakin buruk iklim organisasi suatu perusahaan maka semakin rendah tingkat SWB karyawan di perusahaan tersebut. Berikut ini merupakan tabel hasil uji korelasi antara iklim organisasi dengan SWB:

\section{Tabel 1. Hasil uji korelasi antara iklim organisasi dan SWB}

\begin{tabular}{lllll}
\hline \multirow{2}{*}{$\begin{array}{l}\text { Dimensi } \\
\text { iklim }\end{array}$} & \multicolumn{4}{l}{ Dimensi kebahagiaan } \\
\cline { 2 - 5 } Kepuasan & \multicolumn{3}{l}{ Afeksi } \\
\cline { 2 - 5 } & Nilai & Nilai & Nilai & Nilai \\
& $r$ & $p$ & $r$ & $p$ \\
\hline Struktur & 0.418 & 0.000 & 0.295 & 0.009 \\
Tanggung & 0.401 & 0.001 & 0.282 & 0.013 \\
jawab & & & & \\
Reward & 0.483 & 0.000 & 0.347 & 0.003 \\
Risiko & 0.327 & 0.004 & 0.081 & 0.264 \\
Kehangatan & 0.410 & 0.000 & 0.369 & 0.001 \\
Dukungan & 0.560 & 0.000 & 0.294 & 0.010 \\
Standar & 0.237 & 0.031 & 0.161 & 0.103 \\
Berani & 0.247 & 0.026 & 0.323 & 0.005 \\
berkonflik & & & & \\
Identitas & 0.513 & 0.000 & 0.378 & 0.001 \\
\hline
\end{tabular}

Berdasarkan dari tabel di atas dapat diketahui bahwa mayoritas dimensi dari iklim organisasi memiliki nilai $p<0.05$ dan $r$ $>0.3$ sehingga dapat dikatakan memiliki hubungan dengan dimensi kepuasan dan afeksi dari SWB. Hanya dua dimensi saja yaitu dimensi standar dan risiko yang memiliki nilai $p>0.05$ dan $r<0.3$ sehingga dikatakan tidak memiliki hubungan yang signifikan dengan dimensi afeksi SWB.

Menurut Litwin \& Stringer, dimensi standar adalah mengukur seberapa pentingnya perilaku melakukan pekerjaan dengan baik sebagai bentuk perwujudan tujuan individu ataupun organisasi (dalam Hardjana, 2006). Dari hasil olah data diketahui bahwa dimensi standar tidak berkorelasi dengan dimensi afeksi dari SWB walaupun telah berkorelasi dengan dimensi kepuasan dari SWB meskipun memiliki nilai korelasi yang kecil $\mathrm{r}=0.237 ; \mathrm{p}=0.031(r$ $<0.3 ; p<0.05$ )

Hal ini memunculkan asumsi dimana para karyawan dianggap telah merasa puas atas standar kinerja yang mereka jalankan secara kognisi saja. Dengan melihat nilai korelasi kepuasan yang kecil serta nilai korelasi afeksi yang menunjukkan tidak adanya hubungan yang signifikan maka perlu dilakukan pemeriksaan kembali standar seperti apa yang dipersepsikan oleh karyawan di perusahaan $\mathrm{X}$.

Dimensi risiko tidak memiliki korelasi dengan dimensi afeksi dari SWB namun memiliki korelasi dengan dimensi kepuasan. Secara kognisi, para karyawan di 
perusahaan $\mathrm{X}$ memahami akan pentingnya pengambilan risiko dalam bekerja. Hanya saja disamping pengambilan risiko yang mereka lakukan itu, sisi afeksi mereka mengalami pergolakan. Timbulnya afek negatif dalam proses pengambilan risiko yang dilakukan para karyawan menunjukkan adanya kebutuhan rasa aman yang menuntut untuk dipenuhi.

\section{SIMPULAN DAN SARAN}

Terdapat hubungan positif antara iklim organisasi dengan subjective well being pada karyawan di perusahaan $\mathrm{X}$ dengan nilai korelasi $(r=0.623, p=0.000$ dan $r=0.434$, $p=0.000)$. Sumbangan efektif iklim organisasi terhadap kepuasan SWB adalah sebesar $38.81 \%$. Sementara itu, sumbangan efektif iklim organisasi terhadap afeksi SWB adalah sebesar $18.83 \%$. Faktor-faktor lain yang diduga memiliki keterkaitan dengan
SWB karyawan adalah jenis kelamin, usia, pendapatan, status dan pendidikan terakhir karyawan.

Saran bagi karyawan perusahaan $X$, agar memiliki dan menetapkan tujuan dalam bekerja serta tidak takut untuk meraihnya. Membangun dan membina relasi yang baik dengan rekan-rekan kerja dengan terlibat aktif. Bekerja dengan komitmen, bertanggung jawab dan memiliki rasa cinta terhadap pekerjaan. Bagi kepala divisi dan general manager perusahaan $X$, agar mengenal kembali karakteristik karyawannya. Mempelajari gaya kepemimpinan. Bagi perusahaan $X$, agar terus memprasaranai kebutuhan perkembangan para karyawan. Bagi peneliti selanjutnya. Dapat menggunakan populasi yang berbeda agar semakin memperkaya pengetahuan akan hubungn iklim organisasi dengan SWB. Menggunakan konsep kebahagiaan yang berbeda.

\section{Daftar Pustaka}

Affandi, H. (2002). Pengaruh iklim organisasi terhadap kepuasan kerja, komitmen dan kinerja pegawai (studi kasus pada pegawai di lingkungan pemerintah Kota Semarang). Program Studi Magister Manajemen Universitas Diponegoro, Semarang.

Alfian, G.(2012). Pengaruh kepemimpinan terhadap kepuasan kerja dan produktivitas kerja karyawan pada PT. Taspen (PERSERO) cabang Yogyakarta. Program Studi Akuntansi Universitas Negeri Yogyakarta, Yogyakarta.

Ariati, J. (2010). Subjective well-being (kesejahteraan subjektif) dan kepuasan kerja pada staf pengajar (dosen) di lingkungan fakultas psikologi Universitas Diponegoro. Jurnal Psikologi Undip, 8(2), 117-123.

Azwar, S.D. (2005). Metode penelitian. Yogyakarta: Pustaka Belajar.

Azwar, S.D.(2007). Tes prestasi fungsi dan pengembangan pengukuran prestasi belajar. Yogyakarta: Pustaka Belajar
Azwar, S.D. (2008). Penyusunan skala psikologi. Yogyakarta: Pustaka Belajar.

Baumgardner, S. R., \& Crothers, M. K. (2010). Positive psychology. New Jersey: Pearson Education, Inc.

Boehm, J.K. \& Lyubomirsky, S. (2008). Does happiness promote career success?Journal of Career Assesment, 16(1), 101-116.

Compton, W. (2005). Introduction to positive psychology. Belmont: Thomson Learning Academic Resource Center.

Dewi, P., \& Utami, M. (2013). Subjective wellbeing anak dari orang tua yang bercerai. Jurnal Psikologi, 35(2), 194-212.

Diener, E. (1984). Subjective well being. Pschological Bulletin, 95(3), 542-575.

Diener, E. (2000). Subjective well-being: the science of happiness and proposal for a national index. American Psychologist, 55(1), 34 -43.

Diener, E., Wirtz, D., Diener, R.B., Tov, William., Prieto, C.K., Choi, D.W.,Oishi,S.(2009).New 
measures of well-being. Social Indicators ResearchSeries 39,247 248.

Diener \& Larsen. (1985). Intensity and frequency: dimensions underlying positive and negatif affect. Journal of Personality and Social Psychology, 48(5), 1253-1256.

Diener, E \& Myers, D.G. (1995). Who is happy? Psychological Science, 6(1),1019.

Diener, E., Suh, E. M., Lucas, R. E., \& Smith, H. L. (1999). Subjetive well-being: three decades of progress. Psychological Bulletin, 125(2), 276-302.

Eddington, n. \& Shuman, r. (2005). Subjective well being (happiness). Continuing psychology education: 6 continuing education hours. Diunduh pada 10 November 2014dari http://www.texcpe.com/cpe/PDF/ a-happiness.pdf.

Feist, J \& Feist, G.J (2010). Teori kepribadian, theories of personality. (7th ed).Jakarta : Salemba Humanika

Gatari, E. (2008). Hubungan antara perceived social support dengan subjective wellbeing pada ibu bekerja. Program Studi Pascasarjana Universitas Indonesia, Depok.

Goodwin, R. \& Plaza, S.H. (2000). Perceived and received social support in two cultures: collectivism and support among British and Spanish students. Journal of Social andPersonal Relationship, 17, 282-291.

Handayani, S. (2011). Hubungan antara selfesteem dengan subjective well being karyawan UIN Syarif Hidayatullah Jakarta. Program Studi

Pascasarjana Universitas Islam Negeri Syarif Hidayatullah, Jakarta.

Hardjana, A. (Juni 2006). Iklim organisasi: lingkungan kerja manusiawi. Jurnal Ilmu Komunikasi, 3(1), 1-36.

Hasrian, N. (2009). Pengaruh iklim terhadap kepuasan kerja studi kasus: sekolah menengah atas negeri (SMAN) A kota Depok Provinsi Jawa Barat. Program Studi Sarjana Reguler Manajemen Universitas Indonesia, Depok.

Holloway, J. B. (2012). Leadership behavior and organizational climate: an empirical study in a non-profit organization.
Emerging Leadership Journeys, 5(1), 935.

Tsai Chen Li. (2008).Accessing organizational climate and leadership as a means to evaluate potential for organizational change. The Journal of Human Resource and Adult Learning, 4(1), 47-56.

Mubiono, D. (2010). Pengaruh iklim organisasi, karakteristik kerja, komitmen karyawan dan kepuasan kerja terhadap perfomansi kerja karyawan di PDAM Surya Sembada Kota Surabaya. Program Pascasarjana Universitas Pembangunan Nasional, Surabaya.

Muhadi. (2007). Analisis pengaruh kepuasan kerja terhadap komitmen organisasional dalam mempengaruhi kinerja karyawan (studi pada karyawan administrasi Universitas Diponegoro). Program Pascasarjana Universitas Diponegoro, Semarang.

Mujamiasih, M. (2013). Subjective well-being $(S W B)$ : studi indigenous pada pns dan karyawan swasta yang bersuku Jawa di pulau Jawa. Program Pascasarjana Universitas Negeri Semarang, Semarang.

Nayana, F. (2013). Kefungsian keluarga dan subjective well-being pada remaja. Jurnal Ilmiah Psikologi Terapan, 1(2), 230-244.

Ningsih, D. (2013). Subjective well-being ditinjau dari faktor demografis (status pernikahan, jenis kelamin, pendapatan). Jurnal Online Psikologi, 1(2), 581-603.

Novliadi, F. (2007) Intensi turnover karyawan di tinjau dari budaya perusahaan dan kepuasan kerja.Program Pascasarjana Universitas Sumatera Utara,Medan.

Page, K. (2005). Subjective wellbeing in the workplace. Bachelor Degree Faculty of Health and Behavioural Science Deakin University, Melbourne.

Pujiati, S.A \& Rusliah, N. (n.d.). Penggunaan $R$ dalam Psikologi. Berbagi.Net Academic Publisher.

Rego, Armenio \& Cunha., Miguel Pina e. (2008). Authentizotic climates and employee happiness: pathways to individual performance? Journal of Business Research, 61(7), 739-752.

Reksoatmodjo,T.N.(2009). Statistika untuk psikologi dan pendidikan.

Bandung: PT. Retika Aditama. 
Rufaedah, Any. (2012). Hubungan antara self construal dan subjective well being pada etnis Jawa. Program Pascasarjana Universitas Indonesia, Depok.

Ruswanti, Rosita \& Januarko. (2013). Aplikasi teori kebutuhan ERG Alderfer terhadap motivasi karyawan rumah sakit Islam Hidayatullah Yogyakarta. Forum Ilmiah, 10(2), 166-171.

Ryan, R. M., \& Deci, E. L. (2001). On happiness and human Potentials; a review of research on hedonic and eudaimonic well-being. Annual Review Psychology, 141-166.

Suharto dan Budi Cahyono. 2005, Pengaruh budaya organisasi, kepemimpinan dan motivasi kerja terhadap kinerja sumber daya manusia, di sekretariat DPRD Propinsi JawaTengah, JRBI, 1(1), 13-30.

Suyanto. (2012, Februari 27). Karyawan konflik, PT Freeport hentikan operasional. Surya Online. Diunduh dari http://surabaya.tribunnews.com/ 2012/02/07/karyawankonflik-ptfreeporthentikan-operasional

Triawan \& Sumaryono. (2008). Kecenderungan perilaku pengambilan resiko dengan minat wirausaha. Psikologika Edisi, 26 (13), 22-27.

Venhooven R. (2009). World database of happiness tool for dealing with the "datadeluge". Psychological Topic, 18(2), 221-246.

Wibisono, A. (2008). Pengaruh iklim organisasi terhadap kepuasan kerja (studi tentang pengaruh iklim organisasi terhadap kepuasan kerja pegawai puskesmas Turen di Malang. Jurnal Aplikasi Manajemen, 9(3), 1000-1010.

Yoo, S. J., Huang, W. H., \& Lee, D. Y. (2012). The impact of employee's perception of organizational climate on their techonology acceptance toward elearning in South Korea. Knowledge Management \& E-Learning : An International Journal, 4(3), 359-378.

Yuliana, E. (2007). Hubungan antara iklim organisasi dan kualitas pelayanan pada karyawan McDonald's Java Semarang. Program Pascasarjana Universitas Diponegoro, Semarang.

Yus. (2011, Juli 7). Konflik antar karyawan di Freeport pengaruhi produksi tambang emas. Rima News. Diunduh dari http://www.rimanews.com/read/2011070 7/33919/konflik-antarkaryawan-di freeport-pengaruhi-produksi-tambangemas 